\title{
Performance model development for assessing maintenance service providers using the Kano model
}

\author{
Moses Laksono Singgih \\ Putu Dana Karningsih \\ Mokh Suef \\ Department Industrial Engineering \\ Sepuluh Nopember Institute of Technology, Surabaya, Indonesia \\ Primahasmi Dalulia \\ Department Industrial Engineering \\ University of Merdeka Malang, Malang, Indonesia
}

\section{Keywords}

ICU, Medical equipment, Outsourcing, maintenance service provider, performance model

\begin{abstract}
Outsourcing is delegating partial or total business functions to other companies in conjunction with administrative and operational activities. One of the industries that implements outsourcing in its maintenance activity is the healthcare industry. An Intensive Care Unit (ICU) is part of a hospital which is very vital, so that it requires medical equipment with high availability and reliability. The aim of this research is to develop a performance model to use to assess the performance of medical equipment or the used maintenance outsourcing service providers. Developing the performance model involves 14 criteria. The 14 criteria were clustered by the Kano Model to obtain the importance of each criteria. . Kano was used to identify the criteria within the dimension of basic requirements and special requirements. DEMATEL was employed to identify the connection between criteria and ANP in order to provide the integrity of the criteria. The three criteria with the highest integrity rating were the technicians' capability by the rate of integrity that reached 0.256881 , the aptitude of providing diagnosis by the rate of integrity that reached 0.222181 , and the flexibility by the rate of integrity that reached 0.175684 . Two criteria which had a rate of integrity of 0 and were considered as therefore having the lowest integrity rate were the criteria of charges and dependability respectively.
\end{abstract}

Corresponding author: Moses Laksono Singgih

Email address for corresponding author: moseslsinggih@ie.its.ac.id

First submission received: $10^{\text {th }}$ January 2018

Revised submission received: $19^{\text {th }}$ March 2018

Accepted: 27th March 2018

\section{Introduction}

There are two types of maintenances, i.e., preventive maintenance and corrective maintenance. Preventive maintenance includes maintenance activities that are performed before the system experiences a breakdown, which includes inspections and spare part replacement. The intent of preventive maintenance is to improve on one or more criteria, such as the maintenance cost, reliability, and availability. On the other hand, corrective maintenance refers to maintenance activities that are performed after the system has experienced a breakdown (Nosoohi \& Hejazi, 2011). Usually, all maintenance activities, both corrective and preventive, are performed internally by an internal maintenance department. However, it is now common to outsource the performance of these activities.

Outsourcing is the delegation of a business function to one or more companies, along with the associated administrative and operational activities (Gomez et al., 2009). There are many reasons why companies implement outsourcing, including when the maintenance department is not able to operate economically, or when the company needs flexibility in order to respond to changes in the market that they serve. Hospitals now outsource their maintenance activities in order to focus on health services. On the other hand, medical equipment requires high availability and reliability because it is used to ensure 
patient safety. The Intensive Care Unit (ICU) is a very important hospital area for treating critical patients, therefore, the availability and reliability of ICU medical devices should be given high priority. It is crucial that the maintenance service provider has a high enough performance to achieve that goal. The aim of this study is to develop a performance measurement model that can be used to assess maintenance service providers.

This study proposes a model that is used to measure the performance of the maintenance service provider for ICU equipment. This research is restricted only for maintenance service provider for ICU equipment. The criteria were developed in the previous research study conducted by Singgih \& Dalulia (2016). From the set of criteria has been established, these criteria were classified according to the level of importance using the Kano method. The provider expects to know which criteria are expected by the maintenance service provider users. This is so then the providers can improve the appropriate services. Previous papers have focused on the relationship between each criterion and the associated level of performance, whereas the current research has focused instead on the relationship links between the criteria and the weighting of each criterion. The importance of describing the relationship between the criterions is to emphasise that each criterion has been affected by the other criterion. Defining the importance classification of each criteria also involves the participation of the users of the maintenance service provider by using the principle of Multi-Criteria Decision-Making. The aim of this study is to develop a performance measurement model that can represent the real conditions between the user's aspirations, the maintenance service provider and the medical device's condition. This is so then the model produced can be used by the user as decision-maker within the maintenance department to evaluate the maintenance service provider periodically.

\section{Literature Review}

Cruz \& Rincon (2012) mentioned that there have been a few research studies focused on outsourcing maintenance including provider selection, evaluation and performance appraisal. This paper aims to map the previous studies on outsourcing maintenance. The overall objective of this study is to identify the measurement of the maintenance performance of outsourcing in relation to medical devices in hospital, using a qualitative or quantitative approach. The mapping process in this research was used to define the strategies of the previous research, to find the previous research literature, to conduct the selection of the relevant research studies, and data analysis. The disadvantages of the previous studies include the absence of the mention of management theory used to reinforce the findings of the research, which makes it difficult to apply the results appropriately. In addition, the proposed mathematical model uses assumptions that cannot be applied to real conditions in the field. Some mathematical models can only be applied to a particular industry type, which is not applicable to other industries.

This research only describes the condition of the previous studies in the field of outsourced maintenance, but has not specified what can be examined in the field of outsourcing maintenance. The results gained from this research are that the mapping review produced is been specific, so then it can be determined which area has already been discussed in upcoming research. Almeida (2005) stated that every alternative to contract repair or maintenance activities is determined by several characteristics, such as response time, quality service, dependability and related costs. This study focused on a quantitative approach involving the decision-maker's judgment using multi-criteria decision-making approach. The purpose of this study was to find the best alternative criteria to determine the performance of the maintenance service provider. The multi-criteria method used was the utility theory, in order to evaluate each criterion based on its utility function. The second method was ELECTRE, which was used to evaluate the alternative combinations of all criteria. The criteria developed in this study do not describe how involved the decision-maker is in determining the criteria preference. The number of criteria was too small, so there may be more alternatives that have the same preference results from the decision-maker. The same research conducted by Almeida (2007) was about modelling contract selection for outsourcing. This study is more general than that conducted by Almeida (2005). This study focused on the selection of outsourcing, without any limitations on outsourcing in certain areas. The criteria developed were also general; dependability, cost, and time. The advantage of this research is its general nature, so then it can be applied to any type of industry. However, the criteria developed in this study still does not clearly describe how the decision maker is involved in determining the preferences. 
The purpose of Cruz et al's study (2013) was to identify the characteristics of the service provider's maintenance that directly affected the service quality, measuring the co-variable risk changes to the service quality in terms of turnaround time (TAT) equipment time. For medical equipment, the maintenance activities being performed by a third party is already a common thing. The method used in this study involved statistical tools, which determined the relationship between the criteria and the influence of each criterion on the performance maintenance service provider. However, this study did not involve a decision-maker to determine how much the criteria contributed to the performance measurement of the service provider's maintenance and the combination of the criteria used.

This research used the concept of outsourcing maintenance performance measurements using criteria, which was used in each phase of the outsourcing maintenance problem. The resulting model is used by health industry players to consider the performance measurement of their outsourced maintenance. The research idea was obtained from Cruz \& Rincon's (2012) study on a mapping review of outsourced maintenance for medical equipment. The healthcare industry is a service industry that is closely related to human life and safety. The characteristics of the healthcare industry are unique when compared to the manufacturing industry. In Indonesia, the performance measurement of outsourced maintenance generally has not been conducted by the service user, that is, a hospital. The performance criteria were obtained from Cruz et al. (2013), Almeida (2005), Almeida (2007), Liou \& Chuang (2010) and Singgih \& Dalulia (2016). However, Cruz et al's (2013) research focused on the correlation of each criterion to delivery service, where there is no interest level preference in relation to the weighting form of the criteria. In addition, there was no continuous use in the study.

Almeida (2005) and Almeida (2007) developed selection criteria for outsourcing maintenance, weighted the criteria with utility theory, and elected to use ELECTRE, one of the MCDM methods. This research did not provide the steps in relation to developing the criteria. Criteria development can be conducted by case study analysis, including collecting, comparing and confirming the criteria used and discovering what is considered to be important by the user of the outsourcing maintenance service. A case study analysis was conducted on five Class B Hospitals in East Java. This study required the participation of the decision-makers in the field of maintenance in each hospital. The experts provided an assessment for as long as the research took place. The criteria obtained from the literature study were confirmed for each user. After obtaining the criteria considered important by the user, they were compared and selected using Kano principles. After obtaining the criteria, namely the basic and additional attributes, they were then weighted against each of the criteria. Several weighting methods have been proposed by previous research, including the Multi Attribute Utility Theory (MAUT) proposed by Almeida (2005) and Almeida (2007). Another weighting method is the integration of DEMATEL and ANP, proposed by Lee et al. (2011) and Liou \& Chuang (2010), where the method considers the interrelation between the criteria. The MAUT method does not consider the interconnection between the criteria, so in this study, we used the integration between DEMATEL and ANP. After the criteria were obtained, a measuring instrument for outsourcing the maintenance performance was performed on the list of criteria and their weight.

\section{Research Method}

\subsection{Performance Criteria}

Performance measurement is a quantitative indicator that can be used to measure the achievement of a particular goal, to detect changes over time, and to identify differences within the changes in a given program. Dewangan \& Godse (2014) stated that the absence of a performance measurement method will make it difficult to measure the achievement of a particular goal. In Yildiz \& Demirel (2014), it was stated that the performance of outsourcing will affect the performance of the company. In hospitals, the performance of the maintenance service providers is directly related to patient safety, as medical equipment with low availability has the potential to be the greatest risk to the patient. Therefore, this study has fulfilled the necessity of creating a performance measurement model to assess maintenance service providers in hospitals. Singgih \& Dalulia (2016) developed 14 criteria to assess maintenance service provider performance. The 14 criteria have been stated in Table 1 below. 
Table 1. Criteria for Maintenance Service Provider

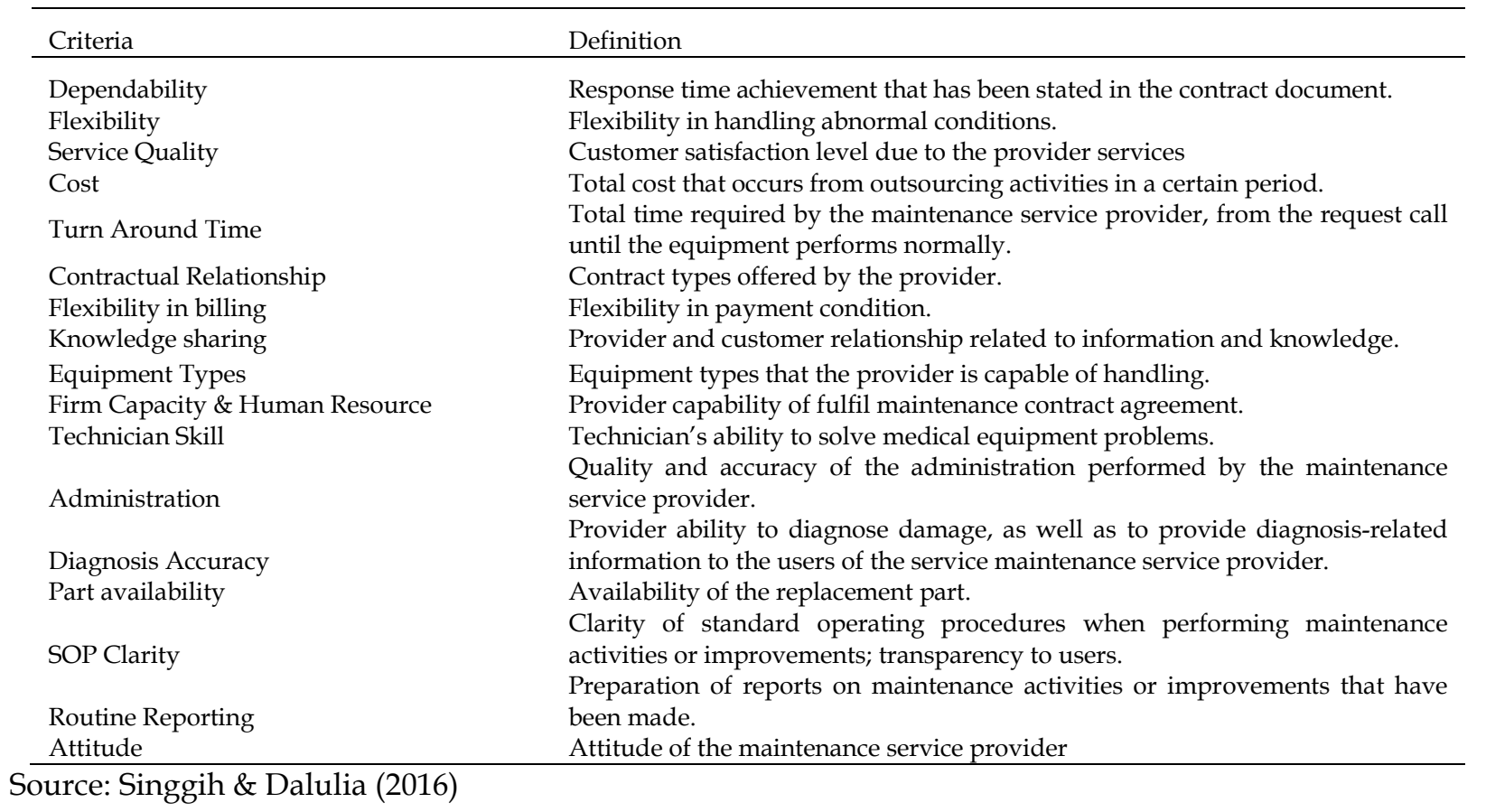

\subsection{Kano Model}

The Kano model classifies the products' features into five categories, namely 'must be', which is a basic attribute, 'one-dimensional', which is a performance-related attribute, 'reverse', which is a performance conversely-related attribute, 'indifferent', which is a performance do not change related attribute and 'attractive', which is an excitement related attribute (Basfirinci \& Mitra, 2015; Suef, Suparno \& Singgih, 2017). Attributes that are classified as 'must be' are defined as the basic features which are essential for every consumer related to customer satisfaction. If this basic feature cannot be fulfilled, then it will lead to consumer dissatisfaction. For example, the repair of equipment must continue until the equipment functions normally. In addition to the categories listed, there are two additional classifications used within the Kano model, namely 'indifference' and 'reverse'. Indifference attributes are attributes that do not affect the level of satisfaction of the consumer, whereas a reverse classification is applied to attributes that lead to consumer dissatisfaction. The Kano model was used because the principles of the basic and special requirements are identified in detail. In addition to the criteria defined as the basic and special requirements, the principles of Kano can also identify any non-essential criteria that can be removed without affecting the consumer perception of the product or service.

In this study, the desired outcome of the case study analysis was to determine what basic and additional criteria are needed. Kano principles were used to select the attributes or criteria that constitute the basic and additional features of the maintenance service provider. Criteria that do not affect the outcome will be eliminated from the list of criteria that influence the performance of the maintenance service provider. The following steps were performed when implementing the Kano model: 1 . identify the product or services requirement, 2. develop the Kano questionnaire, and 3. plot the Kano matrix by calculating the extent of satisfaction and dissatisfaction using (1) and (2).

$$
\begin{aligned}
& \text { Extent of satisfaction }=\frac{A+O}{A+O+M+I} \\
& \text { Extent of dissatisfaction }=\frac{O+M}{(A+O+M+I) \times(-1)}
\end{aligned}
$$

Using the Kano Model approach, the criteria will be classified into groups based on the level of importance of the user. By recognising the importance of each criteria, the maintenance service provider can focus more on the development of services that are important and expected by the users of the maintenance service provider. 


\subsection{DEMATEL-ANP Integration}

DEMATEL is a method that can be used to determine the links between various criteria. In addition to being able to capture the pattern of links between the criteria, the DEMATEL method is also able to capture and analyse the dominant criteria within a particular system. Lee et al., (2011) integrated the DEMATEL and ANP methods to analyse the corresponding relationships between the factors in their study. If the relationships between the factors affecting an investment are known, then the decisionmaking process is expected to be more effective and efficient. The DEMATEL method can be used to investigate the relationship between the factors of a stock investment, followed by the use of ANP to evaluate the magnitude and links between the factors. The DEMATEL method is often applied to effectively arrange problems that have links between the factors. The steps for implementing DEMATEL are as follows: 1 . construct an evaluation scale, 2. develop the direct relationship matrix, 3 . develop the normalisation matrix, 4. construct the total relationship matrix, 5. calculate the importance and relationship values and 6. develop the network relationship matrix (NRM). ANP is designed to accommodate the relationship and interdependence criteria and can complement weaknesses in the Analytical Hierarchy Process (AHP). ANP can be seen of as a generalisation of AHP. The fundamental difference between AHP and ANP is that ANP is used in multi-criteria decision-making and focuses on the corresponding relationships between the criteria, while AHP assumes that there is no link between the criteria and only explores the hierarchical relationships. ANP is able to represent the level of interest of various parties while taking into account the interdependence of any existing criteria and sub-criteria. A weighting calculation using ANP can be performed using the Super Decision software package.

\section{Results and Discussion \\ 4.1 Results}

The criteria which were collected were used to construct the performance model. Before assigning suitable weights, the criteria were evaluated using the Kano Model and separated into the five dimensions mentioned previously. The criteria developed from the Kano model have been illustrated below.

Table 2 - Kano Dimension

\begin{tabular}{ll}
\hline Criteria & Dimension \\
\hline Dependability & one dimensional \\
Flexibility & must be \\
Service Quality & one dimensional \\
Cost & attractive \\
Turn Around Time & indifferent \\
Contractual Relationship & indifferent \\
Flexibility in billing & indifferent \\
Knowledge sharing & one dimensional \\
Equipment Types & must be \\
Finn Capacity & one dimensional \\
Technician Skill & one dimensional \\
Administration & one dimensional \\
Diagnosis Accuracy & one dimensional \\
Part Availability & attractive \\
SOP Clarity & one dimensional \\
Routine Reporting & attractive \\
Attitude & one dimensional \\
\hline
\end{tabular}

Source: calculation

The indifference criteria, such as the turn-around time, flexibility in billing, and contractual relationship, should be eliminated because they have no impact on the performance. The gathered criteria should be weighted based on the importance definition by integrating the results from DEMATEL and ANP. As the significance matrix has been defined, the ANP operation can be performed using the Super Decision software. The significance matrix was used in the development of the criteria relationship model, and the output of the ANP operation was the weight of each criterion. The criteria weights have been illustrated in Table 3 below. 
Table 3 - Criteria Weighting

\begin{tabular}{lll}
\hline Notation & Criteria & Weight \\
\hline C1 & Dependability & 0.0 \\
C2 & Flexibility & 0.175684 \\
C3 & Service Quality & 0.053293 \\
C4 & Cost & 0.0 \\
C5 & Knowledge sharing & 0.005496 \\
C6 & Equipment Types & 0.018238 \\
C7 & Firm Capacity & 0.132503 \\
C8 & Technician Skill & 0.256881 \\
C9 & Administration & 0.041585 \\
C10 & Diagnosis Accuracy & 0.222181 \\
C11 & Part Availability & 0.01998 \\
C12 & SOP Clarity & 0.00914 \\
C13 & Routine Reporting & 0.045708 \\
C14 & Attitude & 0.019312 \\
\hline
\end{tabular}

Source: calculation

Total Score $=0.175684$ C2 +0.053293 C3 +0.005496 C5 +0.018238 C6 +0.132503 C7 +0.256881 C $8+$ 0.041585 C9 + 0.222181 C10 + 0.01998 C11 + 0.00914 C12 + 0.045708 C13 0.019312 C14.

\subsection{Discussion}

The flexibility criterion in the must-be category had the third highest weighting out of the 14 proposed criteria. The first and second ranked criteria, namely technician skill and diagnostic accuracy, were the criteria proposed by Expert 1 according to the assigned weighting. The criterion for technician skill, which was proposed by some experts as a new criterion, was considered to be a uniform criterion, the highest weight of which was considered to be a representation of the real conditions in the field. The criteria of cost and dependability did not contribute to the performance assessment. In addition, the cost criterion was not preferred because it was not a major consideration. This is as it is unlikely to change due to the fact that it is a quantity that has precise numbers involved. Frequently, cost is correlated with the quality of the available facilities. In medical equipment, quality is important because it is related to the safety of the patient, but cost is not the emphasis. The criterion of dependability was not considered to be an important criterion when compared to flexibility. Therefore, in the pair-wise comparison of ANP, the rate of the criterion of flexibility was 9 , which means that it was more important than the criterion of dependability.

\section{Conclusion and Further Research}

By integrating several methods, namely case study analysis, Delphi, Kano, DEMATEL, and ANP, a performance model was developed which can be used by the healthcare industry to assess the performance of the used maintenance service providers. The resulting performance criteria can be used as a reference when assessing the performance of general outsourcing. Case study analysis and Delphi were used to determine the new criteria based on the needs of the user. Kano was used to identify the criteria for the basic and special dimension requirements. DEMATEL was used to determine any linkages between the criteria, and ANP was used to weight the criteria. The results obtained from the Kano method indicated that the criteria that must be fulfilled (basic requirements) also provide flexibility in terms of abnormal situations and the type of equipment that can be handled by the provider (equipment types). The three criteria that had the highest weighting were the criterion of technician skill at 0.256881 , diagnostic accuracy at 0.222181 and flexibility at 0.175684 . The two criteria that were assigned a weight of 0 (meaning that they did not contribute to the performance) were the criteria of cost and dependability.

The model can be enlarged for equipment in another area in the hospital or other types of hospitals. It is suggested that the Ministry of Health creates a special license for maintenance service providers for ICU equipment to control their performance.

\section{References}

Almeida, A. T. (2005). Multicriteria Modelling of Repair Contract Based on Utility and ELECTRE I Method with Dependability and Service Quality Criteria. Annals of Operations Research, (138), pp.113-126.

Almeida, A. T. (2007). Multicriteria Decision Model for Outsourcing Contracts Selection. Computers E Operation Research, (34), pp.3569-3574. 
Angkiriwang, R., Pujawan, I., \& Santosa, B. (2014). Managing Uncertainty Through Supply Chain Flexibility: Reactive vs. Proactive Approaches. Production \& Manufacturing Research: An Open Access Journal, 2(1), pp.50-70.

Basfirinci, C., \& Mitra, A. (2015). A Cross Cultural Investigation of Airlines Service Quality Through Integration of Servqual and the Kano model. Journal of Air Transport Management, (42), pp.239-248.

Cruz, A. M., \& Rincon, A. M. (2012). Medical Device Maintenance Outsourcing: Have Operation Management Research and Management Theories Forgotten the Medical Engineering Community? A Mapping Review. European Journal of Operational Research, (221), pp.186-197.

Cruz, A. M., Rincon, A. M., \& Haugan, G. L. (2013). Measuring the Performance of Maintenance Service Outsourcing. Biomedical Instrumentation and Technology, 6(47), pp.524-531.

Dewangan, V., \& Godse, M. (2014). Towards A Holistic Enterprise Innovation Performance Measurement System. Technovation.

Gomez, J. F., Parra, C., Gonzales, V., Crespo, A., \& de Leon, P. M. (2009). Outsourcing Maintenance in Services Providers. Safety, Reliability and Risk Analysis: Theory, Methods and Applications.

Lee, W.-S., Huang, A. Y., Chang, Y.-Y., \& Cheng, C.-M. (2011). Analysis of Decision-Making Factors for Equity Investment by DEMATEL. Expert Systems with Applications, (38), 8375-8383.

Liou, J. J., \& Chuang, Y.-T. (2010). Developing A Hybrid Multi - Criteria Model for Selection Of Outsourcing Providers. Journal of Expert Systems with Applications, (37), pp.3755 - 3761.

Nosoohi, I., \& Hejazi, S. R. (2011). A Multi-Objective Approach to Simultaneous Determination of Spare Part Numbers and Preventive Replacement Times. Applied Mathematical Modelling, 35, pp.1157-1166

Singgih, M. L., \& Dalulia, P. (2016). Performance Criteria Development of Maintenance Service Provider Using Case Study Approach Analysis. International Joint Conference of 2016 2nd International Conference of Industrial, Mechanical, Electrical, and Chemical Engineering (ICIMECE) and 2016 Annual Conference on Industrial and System Engineering (ACISE). Yogyakarta: Universitas Sebelas Maret.

Suef, M., Suparno, S., Singgih., M.L. (2017). Categorizing Product Attributes Efficiently In Qfd-Kano: A Case Analysis In Telecommunication. The TQM Journal, 29(3), pp. 512 - 527

Yildiz, S., \& Demirel, Z. H. (2014). The Benefits, Risks, And Effects on Performance of The Outsourcing: A Comparative Study of Seasonal and Permanent Hotels. Procedia Social and Behavioural Sciences, (109), pp.514521. 